\title{
Micronutrient Density and Stability in West African Pearl Millet- Potential for Biofortification
}

\author{
Anna Pucher, Henning Høgh-Jensen, Jadah Gondah, C. Tom Hash, and Bettina I. G. Haussmann*
}

\begin{abstract}
Pearl millet [Pennisetum glaucum (L.) R. Br.] is one of the most important cereals in West and Central Africa (WCA). Human populations in WCA are strongly affected by micronutrient deficiencies. Biofortification, the development of pearl millet varieties with enhanced micronutrient levels, is recognized as a suitable approach to reducing this widespread health problem. To assess the potential of biofortification of WCA pearl millet germplasm, we studied quantitative-genetic parameters of eight mineral densities in whole and decorticated grains, their stability over environments, and the correlations among minerals and agromorphological traits. The study included 72 WCA pearl millet genotypes grown in three environments in Niger, contrasting in soil fertilization. Significant genotypic effects, moderate estimates of heritability, and genetic variation for mineral densities, especially for $\mathrm{Fe}$ and $\mathrm{Zn}$, indicate a high potential for biofortification of WCA pearl millet. However, screening of additional landraces or introgression of favorable alleles from highly nutrient-dense Indian germplasm could expedite achievement of higher densities. Genotype-by-environment interaction effects were significant for $\mathrm{Fe}$ and $\mathrm{Zn}$ grain densities, showing the importance of multienvironmental evaluation for identifying stable genotypes. Identified genotypes with relatively stable Fe and $\mathrm{Zn}$ grain densities appear suitable for use in future WCA pearl millet biofortification breeding programs.
\end{abstract}

A. Pucher and B.I.G. Haussmann, Univ. of Hohenheim, Institute of Plant Breeding, Seed Science and Population Genetics, Fruwirthstr. 21, D-70599, Stuttgart, Germany; H. Høgh-Jensen, National Food Institute, Technical Univ. of Denmark, 2800 Kgs. Lyngby, Denmark; J. Gondah, Institut National de Recherche Agronomique du Niger (INRAN), Maradi, Niger; C.T. Hash, International Crops Research Institute for the Semi-Arid Tropics (ICRISAT), BP 12404 Niamey, Niger. Received 12 Nov. 2013. *Corresponding author (Bettina. haussmann@uni-hohenheim.de).

Abbreviations: AMMI, additive main effects and multiplicative interaction; $\mathrm{G} \times \mathrm{E}$, genotype-by-environment interaction; OPV, open-pollinated variety; PC, principal component; WCA, West and Central Africa.

$M$ iCRONUTRIENT MALNUTRITION affects about two billion people in the world (Muthayya et al., 2013), primarily in developing countries such as those in West and Central Africa (WCA) (Birner et al., 2007). The major cause of this so called "hidden hunger" is insufficiently diversified diets dominated by dietary staple carbohydrate sources, which have low micronutrient density and poor micronutrient bioavailability. Zinc (Zn) and iron $(\mathrm{Fe})$ are the most frequently lacking mineral micronutrients in human diets, whereas other essential minerals such as Calcium $(\mathrm{Ca})$, Copper $(\mathrm{Cu})$, and Magnesium $(\mathrm{Mg})$ can be deficient in some populations' diets as well (White and Broadley, 2005). Focusing on African countries, the risk of insufficient $\mathrm{Mg}$ uptake is relatively low (<4\%), as major cereals like sorghum [Sorghum bicolor (L.) Moench], pearl millet [Pennisetum glaucum (L.) R. Br.], and maize (Zea mays L.) provide adequate amounts of Mg (Joy et al., 2012).

Biofortification is the process of increasing the nutrient densities by breeding or genetic engineering. Biofortification of staple

\footnotetext{
Published in Crop Sci. 54:1709-1720 (2014).

doi: 10.2135/cropsci2013.11.0744

(C) Crop Science Society of America | 5585 Guilford Rd., Madison, WI 53711 USA

All rights reserved. No part of this periodical may be reproduced or transmitted in any form or by any means, electronic or mechanical, including photocopying, recording, or any information storage and retrieval system, without permission in writing from the publisher. Permission for printing and for reprinting the material contained herein has been obtained by the publisher.
} 
crops can be a sustainable and cost-effective approach to combating malnutrition (Bouis, 1999; Meenakshi et al., 2010), especially of rural populations in remote, low-rainfall areas, with limited access to diverse diets, commercially fortified foods, or supplements (Saltzman et al., 2013).

Pearl millet, the most heat-tolerant and one of the most drought- and salinity-tolerant cultivated cereals, is a major food crop for smallholder subsistence farmers living on marginal agricultural lands in the semiarid tropics of Africa and Asia (Haussmann et al., 2012). Pearl millet grain has a relatively well-balanced amino acid composition suitable for human nutrition and higher grain fat, protein, and micronutrient densities than other major cereals like wheat (Triticum aestivum L.), maize, or polished rice (Oryza sativa L.) (Goswami et al., 1969; Sawaya et al., 1984; Khairwal et al., 1999; Dwivedi et al., 2012; Bashir et al., 2013). However, diets predominated by pearl millet are often not high enough in mineral micronutrient density to meet daily minimum requirements. The development of pearl millet varieties with improved grain mineral nutrient densities can be one step to improve the nutrient intake of rural families, especially in the Sahel region of sub-Saharan Africa where pearl millet can contribute 80 to $85 \%$ of daily calorie intake. Pearl millet biofortification, targeting increased grain $\mathrm{Fe}$ densities, has already been successful in India, where a biofortified, open-pollinated variety (OPV) was released in 2012 (Saltzman et al., 2013). Recently published studies report clear increases in $\mathrm{Fe}$ and $\mathrm{Zn}$ absorption when biofortified pearl millet grain of Indian origin is consumed by young women or children (Cercamondi et al., 2013; Kodkany et al., 2013). Biofortified pearl millet grain, fed as the major staple to children younger than $3 \mathrm{yr}$, can even exceed their physiological requirements for Fe and $\mathrm{Zn}$ (Kodkany et al., 2013).

The success of the pearl millet biofortification program in India suggests that a comparable breeding program could be successful in WCA-particularly as the best reported sources of high levels of grain $\mathrm{Fe}$ and $\mathrm{Zn}$ in pearl millet (Velu et al., 2007, 2008, 2011; Govindaraj et al., 2009, 2011, 2013; Gupta et al., 2009; Kumar, 2011; Rai et al., 2012) are all derived from large-grained Iniadi landrace germplasm from Benin, Ghana, and Togo that has contributed so much to Indian pearl millet breeding successes over the past $50 \mathrm{yr}$ (Andrews and Anand Kumar, 1996). Indeed, the biofortified pearl millet OPV recently released in India is derived directly (by two cycles of selection, the first leading to release of improved OPV 'ICTP 8203' [= MP 124] in India in 1988, and the second producing a higher-Fe version of this variety, 'ICTP 8203-Fe', which was released in the Indian state of Maharashtra in 2012 as 'Dhanshakti') from a single Iniadi landrace germplasm accession from Togo (Rai et al., 1990; Saltzman et al., 2013). Genetic variation of grain micronutrient densities in adapted genetic materials is the basic requirement for such biofortification breeding programs and thus should be assessed beforehand. Previous studies on pearl millet with regard to biofortification focused mostly on $\mathrm{Zn}$ and $\mathrm{Fe}$, as these mineral micronutrients are deficient in diets of most human populations. Research on other essential minerals is limited in pearl millet but necessary to evaluate the potential impact of $\mathrm{Fe}$ and $\mathrm{Zn}$ biofortification on other minerals.

Pearl-millet-based dishes consumed in West Africa are traditionally prepared from decorticated grains, whereas nearly all pearl-millet-based dishes consumed in India are traditionally prepared from whole-grain flour. The decortification process is known to reduce mineral densities, and it is therefore relevant to analyze the relationship between whole and decorticated grain mineral densities.

The objectives of our study were to (i) determine the genetic variation and stability of eight grain mineral densities in 72 genotypes of pearl millet from WCA grown in three contrasting environments in Niger; (ii) estimate the genotype, environmental, and genotype-by-environment $(G \times E)$ interaction effects as well as the heritabilities of grain mineral densities; (iii) assess the extent of grain mineral reduction by decortication; (iv) assess the accuracy of whole grain analysis to estimate mineral densities of decorticated grains; (v) assess relationships among minerals and between minerals and agronomic traits; and (vi) describe patterns of geographical distribution of pearl millet grain $\mathrm{Fe}$ and $\mathrm{Zn}$ levels among landraces of WCA origin.

\section{MATERIALS AND METHODS Plant Material and Field Trials}

The plant material consisted of 72 pearl millet genotypes (69 landraces and 3 improved OPVs, viz. ICMV-IS 89305, SOSAT-C88, and Zatib) of early-to-medium maturity, originating from a wide geographic area across WCA. In 2007, the 72 genotypes were grown in three environments in Niger, defined by their site $\times$ soil fertilization combination. Two test environments differing in soil fertilization were established at the ICRISAT research station at Sadoré. One environment received a moderate amount of fertilizer $\left(100 \mathrm{~kg} \mathrm{ha}^{-1}\right.$ of NPK [15-15-15] broadcast before sowing, top-dressed with $50 \mathrm{~kg}$ $\mathrm{ha}^{-1}$ urea) and is therefore referred to as "Sadoré-mod." The other environment, "Sadoré-low," was not fertilized and can be considered as a typical on-farm condition in the target region. The third environment was at the INRAN research station at Maradi, where relatively high amounts of fertilizer were applied $\left(100 \mathrm{~kg} \mathrm{ha}^{-1}\right.$ of super simple phosphate broadcast before sowing, microdosing with $115 \mathrm{~kg} \mathrm{ha}^{-1}$ NPK [15-1515] at sowing and $50 \mathrm{~kg} \mathrm{ha}^{-1}$ urea top-dressing), and thus is referred to as "Maradi-high." In each environment, the trial was laid out in an $\alpha$ design with two replications, nine incomplete blocks per replicate, and eight plots per incomplete block. Each plot had two rows of 4.8-m length and 0.75-m inter-row distance, and alleys were 1.2-m wide. Within rows, hills with two plants each were grown at $0.8-\mathrm{m}$ intervals, so each plot consisted of 14 hills occupying $9 \mathrm{~m}^{2}$ and grown at a density of 15,556 hills ha ${ }^{-1}$. Results for the following agromorphological 
traits are presented here: flowering time (Julian days until 50\% of the main stems in a plot show female stigmas), grain yield $\left(\mathrm{g} \mathrm{m}^{-2}\right)$, and thousand-kernel weight $(\mathrm{g})$.

\section{Micronutrient Analysis}

Open-pollinated grain samples of each replication were analyzed for grain mineral nutrient densities using whole grains (all 72 genotypes) and decorticated grains (a subset of 24 genotypes). For the decortication process, samples of $30 \mathrm{~g}$ dried grain were rinsed with distilled water to remove any dust and then dried again in the oven. Samples were then decorticated by hand using a small manual ceramic mortar, which was also cleaned after each sample.

All grain samples were dried to constant weight at $60^{\circ} \mathrm{C}$. After grinding in a titanium-coated mill (SuperMill 1500, Newport Scientific Europe Ltd.), subsamples of the plant materials were digested in an open-vessel system using 70-mL HD polyethylene vials (Capitol Vial) and a graphite-heating block (Mod Block, CPI International) as described in detail by Husted et al. (2004). In brief, the plant material was first digested for $15 \mathrm{~min}$ in $35 \% \mathrm{HNO}_{3}$ at $95^{\circ} \mathrm{C}$. After cooling, additional $70 \%$ $\mathrm{HNO}_{3}$ was added together with $\mathrm{H}_{2} \mathrm{O}_{2}$. During digestion, the vials were covered with HD-PE watch glasses. Samples were cooled overnight and diluted to $50 \mathrm{~mL}$ with ultra-pure water. After appropriate dilution, the samples were analyzed by ICPMS (Agilent 7500c, Agilent Technologies) for the following elements: $\mathrm{Ca}, \mathrm{Cu}, \mathrm{Fe}, \mathrm{K}, \mathrm{Mg}, \mathrm{Mn}, \mathrm{P}, \mathrm{Zn}$, and Al. To check for Fe contamination through soil dust, Al concentration was taken as an indicator (Pfeiffer and McClafferty, 2007). As Al concentrations were relatively low and not correlated with Fe, we could assume that there was no soil contamination. Measured Ca concentrations for whole grain samples from Maradi did not appear to be reliable owing to very high variation, thus they were excluded from further analysis.

\section{Statistical Analysis}

Data were analyzed by a one-step approach using mixed models. The following mixed model was applied to estimate the variance components of whole grain micronutrient densities:

$$
y_{i j k l m}=\mu+g_{i}+e_{j}+g e_{i j}+r_{j k}+b_{j k l}+\varepsilon_{j k l m}
$$

were $y_{i j k l m}$ represents the observed phenotype on plot basis; $\mu$ the overall experiment mean; $g_{i}$ the genetic effect of genotype $i$, $e_{j}$ the effect of environment $j, g e_{i j}$ the interaction between genotype $i$ and environment $j, r_{j k}$ the effect of replication $k$ nested in environment $j, b_{j k l}$ the effect of incomplete block $l$ nested in replication $k$ and environment $j$, and $\varepsilon_{j k l m}$ the residual effect of the plot $m$ nested in block $l$, replication $k$ and environment $j$. For calculation of adjusted entry means, genetic effects were treated as fixed, and all the other factors as random. For estimation of variance components, only the environmental effect was treated as fixed and all other effects were treated as random. In case of decorticated grain mineral nutrient density analysis of the subset of 24 genotypes, the incomplete block effect $b_{j k l}$ was excluded from the mixed model.

To illustrate the extent of mineral variability at each environment, boxplots were used, and to determine the differences between environments for each mineral, pairwise comparison was done using $t$ tests with Bonferroni corrections.

Broad-sense heritability $\left(h^{2}\right)$ was estimated for each trait individually across environments as $h^{2}=\sigma_{g}^{2} \times\left(\sigma_{g}^{2}+\frac{\sigma_{g e}^{2}}{E}+\frac{\sigma_{\varepsilon}^{2}}{E R}\right)^{-1}$, while plot-based repeatabilities for each environment were calculated as $w=\sigma_{g}^{2} \times\left(\sigma_{g}^{2}+\frac{\sigma_{\varepsilon}^{2}}{R}\right)^{-1}$, with $\sigma_{g}^{2}$ being the genotypic variance, $\sigma_{g e}^{2}$ the $G \times E$ variance, and $\sigma_{\varepsilon}^{2}$ the residual error variance for $R$ replicates and $E$ environments.

The relationships among grain mineral densities and between mineral densities and agronomic traits were first examined for each environment separately using Pearson's correlation coefficients-based entry means of the 72 genotypes (Supplemental Table S2). Afterward, the correlation mean across the three environments was determined. Correlations were considered as significant or highly significant, when the significance level of $p<0.05$ or $p<0.01$ was reached for all three locations, respectively. Correlations between whole grain and decorticated grain mineral density were calculated on the basis of plot values of the 24-genotype subset. A paired $t$ test was used to determine the significance of differences between the whole and decorticated grain mineral densities.

All calculations were performed within the R-environment v. 2.14.2 (R Development Core Team, 2012). Mixed model analyses were performed using the package ASReml v. 3.0 for the R-environment (Butler et al., 2009). AMMI plots were done using the R-package "agricolae” v. 1.1-3 (De Mendiburu, 2012).

\section{RESULTS Means and Ranges}

Moderate variations among the genotypes studied were found for whole grain $\mathrm{Mg}, \mathrm{P}, \mathrm{K}$, and $\mathrm{Mn}$ densities (between 1.2- and 1.5-fold) (Table 1). Calcium, $\mathrm{Fe}, \mathrm{Cu}$, and $\mathrm{Zn}$ densities showed greater variation among genotypes (between 2.0- and 2.2-fold).

The three improved OPVs, SOSAT-C88, ICMV-IS 89305, and Zatib, showed grain Fe densities of $32.7 \mathrm{mg}$ $\mathrm{kg}^{-1}, 28.2 \mathrm{mg} \mathrm{kg}^{-1}$, and $30.7 \mathrm{mg} \mathrm{kg}^{-1}$, and grain $\mathrm{Zn} \mathrm{den-}$ sities of $32.3 \mathrm{mg} \mathrm{kg}^{-1}, 31.4 \mathrm{mg} \mathrm{kg}^{-1}$, and $30.5 \mathrm{mg} \mathrm{kg}^{-1}$, respectively (Supplemental Table S1). Those values are moderately lower than the overall trial means, which were $38.0 \mathrm{mg} \mathrm{kg}^{-1}$ for $\mathrm{Fe}$ and $34.9 \mathrm{mg} \mathrm{kg}^{-1}$ for $\mathrm{Zn}$.

For all nutrients, decortication caused a highly significant $(p<0.001)$ reduction in nutrient density, with average reductions between $7.0(\mathrm{~K})$ and $48.9 \%(\mathrm{Ca})$. The variation of decorticated grain mineral densities for each mineral was similar to that of mineral densities of whole grains (between 1.2- and 2.3-fold).

The means and variation for whole grain mineral nutrient density differed partially between the three environments (Fig. 1). Grain densities of both Fe and $\mathrm{Zn}$ were lowest at Sadoré-low and highest at Maradi-high. For the other minerals, the trend of increasing mineral density with increasing soil fertilization did not apply. For $\mathrm{Mg}$ grain 
Table 1. Means ( \pm standard errors) and ranges of whole and decorticated grain mineral densities in 72 and 24 WCA pearl millet [Pennisetum glaucum (L.) R. Br.] genotypes, respectively, on the basis of adjusted entry means across three field environments in Niger and corresponding means ( \pm standard errors) and ranges for reduction of grain mineral densities due to decortication.

\begin{tabular}{|c|c|c|c|c|c|c|}
\hline \multirow[b]{2}{*}{ Minerals } & \multicolumn{2}{|c|}{ Whole grain density } & \multicolumn{2}{|c|}{ Decorticated grain density } & \multicolumn{2}{|c|}{ Density reduction by decortication } \\
\hline & Mean \pm SE & Range & Mean \pm SE & Range & Mean \pm SE & Range \\
\hline & \multicolumn{2}{|c|}{$\mathrm{mg} \mathrm{kg}^{-1}$} & \multicolumn{2}{|c|}{$\longrightarrow \mathrm{mg} \mathrm{kg}^{-1} \longrightarrow$} & \multicolumn{2}{|c|}{$\%$} \\
\hline $\mathrm{Mg}$ & $1302 \pm 63$ & $1173-1451$ & $1029 \pm 50$ & $855-1236$ & $19.5 \pm 5.3$ & $5.0-30.7$ \\
\hline$P$ & $3209 \pm 153$ & $2835-3507$ & $2651 \pm 193$ & 2213-2974 & $16.6 \pm 5.9$ & $2.6-27.2$ \\
\hline K & $4173 \pm 429$ & $3687-4637$ & $3745 \pm 158$ & $3180-4526$ & $7.0 \pm 10.6$ & $-3.4-18.6$ \\
\hline $\mathrm{Ca}$ & $243.7 \pm 21.1$ & 163.9-347.5 & $107.7 \pm 15.3$ & $68.4-154.6$ & $48.9 \pm 5.2$ & $41.6-60.6$ \\
\hline $\mathrm{Mn}$ & $21.9 \pm 3.4$ & $17.7-27.2$ & $13.9 \pm 1.7$ & $11.2-19.2$ & $33.3 \pm 5.6$ & $23.1-42.4$ \\
\hline $\mathrm{Fe}$ & $38.0 \pm 3.8$ & $24.2-48.7$ & $30.0 \pm 5.0$ & $19.4-44.1$ & $20.5 \pm 7.3$ & $5.7-29.4$ \\
\hline $\mathrm{Cu}$ & $4.6 \pm 0.4$ & $3.1-6.1$ & $3.7 \pm 0.4$ & $2.7-4.3$ & $12.9 \pm 11.8$ & $-14.0-32.1$ \\
\hline $\mathrm{Zn}$ & $34.9 \pm 3.5$ & $19.8-43.4$ & $28.8 \pm 4.5$ & $18.1-36.0$ & $17.4 \pm 7.5$ & $10.6-26.5$ \\
\hline
\end{tabular}
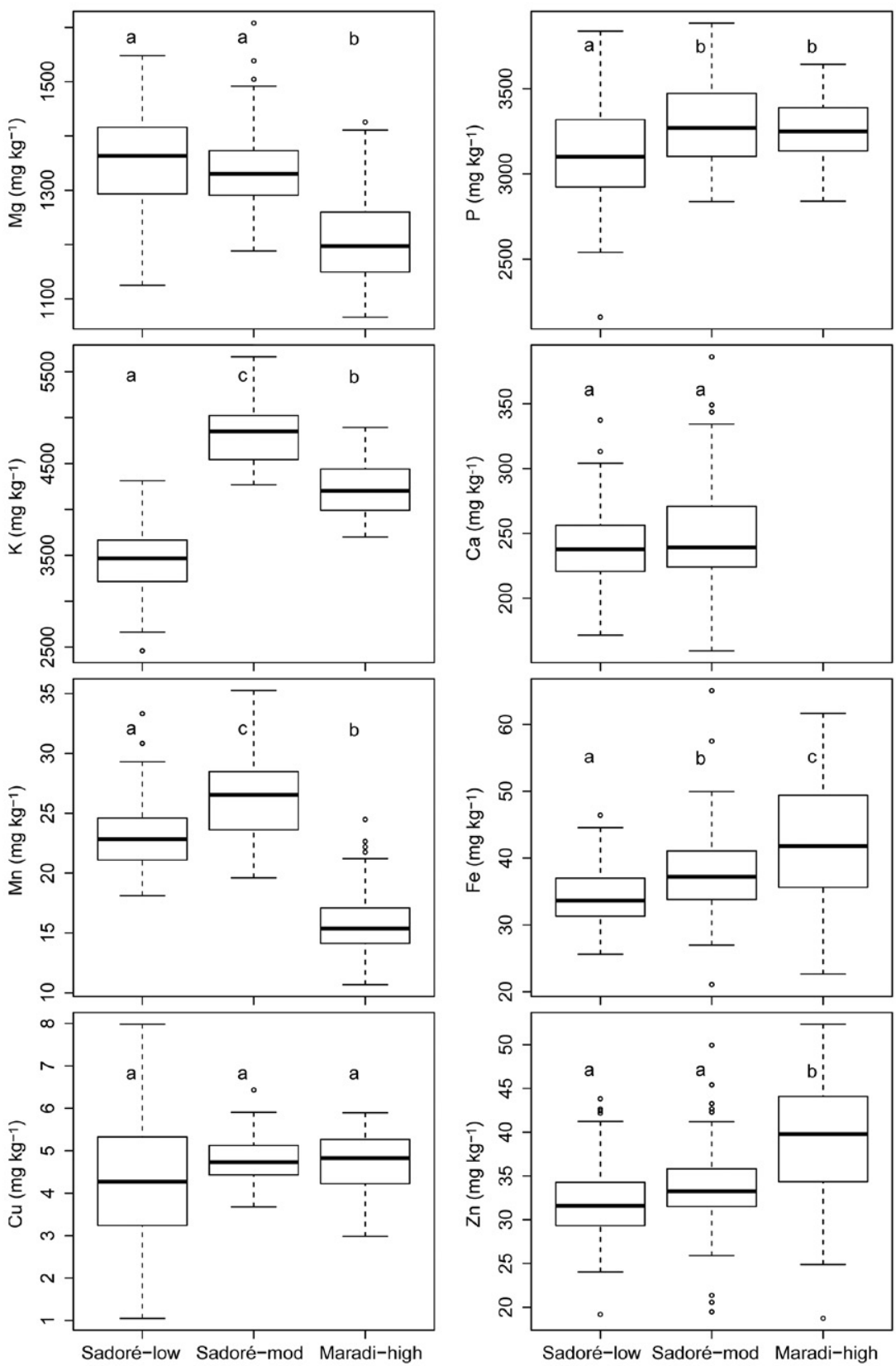

Figure 1. Box plots for whole grain mineral densities, separately for each testing environment (Sadore-low = Sadore site without fertilizer application; Sadore-mod = Sadore site with moderate fertilizer application; Maradi-high = Maradi site with high fertilizer application). Different letters within graphs correspond to significant differences between environments $(p<0.05)$. 
Table 2. Plot-based repeatabilities of whole grain mineral densities and agromorphological traits (TKW, thousand-kernel weight; GY, grain yield; FLO, flowering time) on the basis of 72 pearl millet [Pennisetum glaucum (L.) R. Br.] genotypes evaluated in three field environments in Niger in 2007.

\begin{tabular}{ccccccccccccc}
\hline Environment $^{\dagger}$ & $\mathbf{M g}$ & $\mathbf{P}$ & $\mathrm{K}$ & $\mathrm{Ca}$ & $\mathrm{Mn}$ & $\mathrm{Fe}$ & $\mathrm{Cu}$ & Zn & TKW & GY & FLO \\
\hline Sadoré-low & 0.23 & 0.02 & 0.69 & 0.00 & 0.00 & 0.28 & 0.49 & 0.62 & 0.74 & 0.64 & 0.90 \\
Sadoré-mod & 0.53 & 0.73 & 0.73 & 0.80 & 0.52 & 0.84 & 0.55 & 0.84 & 0.80 & 0.59 & 0.95 \\
Maradi-high & 0.45 & 0.42 & 0.65 & - & 0.64 & 0.83 & 0.68 & 0.79 & 0.72 & 0.48 & 0.80 \\
\hline
\end{tabular}

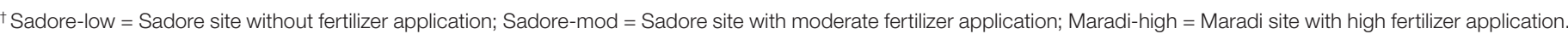

densities this trend was reversed. Grain P densities were not significantly different for Sadoré-mod and Maradi-high but were significantly lower for Sadoré-low. Grain $\mathrm{Ca}$ and $\mathrm{Cu}$ densities did not differ at the different locations (Ca densities were not reliable and therefore not considered for Maradihigh), whereas the $\mathrm{Cu}$ densities varied considerably more at Sadoré-low than at the other two locations. Grain Mn and $\mathrm{K}$ densities were generally quite variable between locations, with highest densities at Sadoré-mod.

Except for $\mathrm{K}, \mathrm{Cu}$, and $\mathrm{Zn}$, plot-based repeatabilities (Table 2) of grain mineral densities were very low at Sadoré-low. At the two locations, where fertilizer was applied, higher repeatabilities were observed, ranging between $0.52(\mathrm{Mn})$ and $0.84(\mathrm{Fe}$ and $\mathrm{Zn})$. Flowering time, which is generally known to have high repeatability and therefore was used as a reference trait, showed high repeatabilities $(0.80$ to 0.95$)$ in all three environments.

\section{Variance Components and Heritability}

Estimates of the genetic variance, $\sigma_{\mathrm{g}}^{2}$, were significant $(p<0.05)$ for all whole grain mineral densities except for $\mathrm{P}$ (Table 3). In case of decorticated grains, $\sigma^{2}$ was significant for $\mathrm{Zn}$ and highly significant for $\mathrm{Mg}, \mathrm{K}, \mathrm{Ca}, \mathrm{Mn}$, and $\mathrm{Fe}$. The estimated variance component of the $\mathrm{G} \times \mathrm{E}$ interaction was significant or highly significant for $\mathrm{P}, \mathrm{Fe}$, and $\mathrm{Zn}$ for whole grain densities as well as for decorticated grain densities. Grain Ca showed a significant $\mathrm{G} \times$ $E$ interaction for decorticated grains, but not for whole grains. Estimates of $h^{2}$ for the different mineral densities ranged from $0.06(\mathrm{P})$ to $0.70(\mathrm{Fe})$ for whole grains and from $0.22(\mathrm{P})$ to $0.81(\mathrm{~K})$ for decorticated grains.

\section{Stability Analysis}

The AMMI plot shows the stability and patterns of $\mathrm{G} \times \mathrm{E}$ interaction of the 72 genotypes for grain $\mathrm{Fe}$ and $\mathrm{Zn}$ density and grain yield over the three environments contrasting in soil fertilization (Fig. 2). The trait means of the genotypes are given on the abscissa and the stability of the genotypes is indicated on the ordinate (principal component [PC] 1) of the AMMI biplot, for which genotypes with PC1 values close to zero can be classified as stable. Those performing proportionally better in the Maradi-high environment showed positive PC1 values and those performing better in Sadoré-low showed negative PC1 values. Genotype 67 ('PE05980') had, for instance, on average the highest grain
Table 3. Variance components with standard errors (SE) for genotypes $\left(\sigma^{2}{ }_{g}\right)$, genotype-by-environment interactions $\left(\sigma^{2}{ }_{g e}\right)$, Wald test indicating significance of environmental effects, and broad-sense heritabilities $h^{2}$ for whole grain minerals determined using 72 pearl millet [Pennisetum glaucum (L.) $\mathrm{R}$. Br.] genotypes, and decorticated grain minerals using a subset of 24 pearl millet genotypes, evaluated in three field environments in Niger in 2007.

\begin{tabular}{|c|c|c|c|c|}
\hline Minerals & $\sigma_{g}^{2} \pm S E$ & $\sigma_{g e}^{2} \pm S E$ & $\begin{array}{c}\text { Wald } \\
\text { test }\end{array}$ & $h^{2}$ \\
\hline \multicolumn{5}{|c|}{ Whole grain density } \\
\hline $\mathrm{Mg}$ & $965^{\star} \pm 533$ & $1577^{\star} \pm 781$ & ** & 0.35 \\
\hline $\mathrm{P}$ & $1144^{\mathrm{ns}+} \pm 3902$ & $17570 * \pm 7514$ & * & 0.06 \\
\hline K & $35,545^{\star \star} \pm 10,596$ & $36,989^{* *} \pm 9833$ & $\star \star$ & 0.60 \\
\hline $\mathrm{Ca}$ & $468^{\star \star} \pm 171$ & $114^{\mathrm{ns}} \pm 170$ & ns & 0.64 \\
\hline $\mathrm{Mn}$ & $1.54^{\star} \pm 0.72$ & $1.00^{\text {ns }} \pm 1.06$ & ** & 0.41 \\
\hline $\mathrm{Fe}$ & $21.15^{\star \star} \pm 5.31$ & $15.28^{\star \star} \pm 3.70$ & ** & 0.70 \\
\hline $\mathrm{Cu}$ & $0.26^{* \star} \pm 0.07$ & $0.18^{*} \pm 0.07$ & ns & 0.62 \\
\hline $\mathrm{Zn}$ & $8.48^{\star \star} \pm 2.92$ & $15.58^{\star *} \pm 2.93$ & * & 0.53 \\
\hline \multicolumn{5}{|c|}{ Decorticated grain density } \\
\hline $\mathrm{Mg}$ & $3779^{\star *} \pm 1932$ & $2640^{\text {ns }} \pm 1775$ & ns & 0.61 \\
\hline $\mathrm{P}$ & $5275^{\text {ns }} \pm 8228$ & $23,528^{*} \pm 13,185$ & ** & 0.22 \\
\hline K & $110,753^{\star \star} \pm 40,964$ & $8781^{\text {ns }} \pm 20,066$ & ns & 0.81 \\
\hline $\mathrm{Ca}$ & $372^{\star \star} \pm 142$ & $157.21^{\star \star} \pm 69.02$ & ** & 0.79 \\
\hline $\mathrm{Mn}$ & $2.42^{\star \star} \pm 1.08$ & $0.55^{\text {ns }} \pm 0.84$ & ** & 0.69 \\
\hline $\mathrm{Fe}$ & $21.93^{\star *} \pm 9.80$ & $14.65^{\star} \pm 7.24$ & ** & 0.68 \\
\hline $\mathrm{Cu}$ & $0.04^{\text {ns }} \pm 0.06$ & $0.18^{*} \pm 0.09$ & ns & 0.25 \\
\hline $\mathrm{Zn}$ & $8.03^{*} \pm 4.28$ & $8.51^{*} \pm 3.96$ & ** & 0.58 \\
\hline
\end{tabular}

* Significant at $P<0.05$.

** Significant at $P<0.01$.

tns Not significant at $P<0.05$.

Fe density but was not stable over environments (PC1 = 1.32). Its high average $\mathrm{Fe}$ grain density was caused by high values observed at Maradi-high (Supplemental Table S1). Genotypes 4 (PE00012) and 49 (PE05665), showed high means for grain $\mathrm{Fe}$ and $\mathrm{Zn}$ densities and were also relatively stable for both mineral micronutrients (Fig. 2). Additionally, landrace PE00012 showed a relatively high mean grain yield $\left(1006 \mathrm{~kg} \mathrm{ha}^{-1}\right)$. Another promising landrace was PE00025 (Genotype 1), as it had very high grain $\mathrm{Zn}$ density and grain yield with reasonable stability.

\section{Correlations among Traits}

Correlations among grain minerals, determined as means of the three environments, were in most cases positive, and in eight of the cases, significant $(p<0.05$ or $p<0.01)$ (Table 4). Notably high positive correlations were observed 

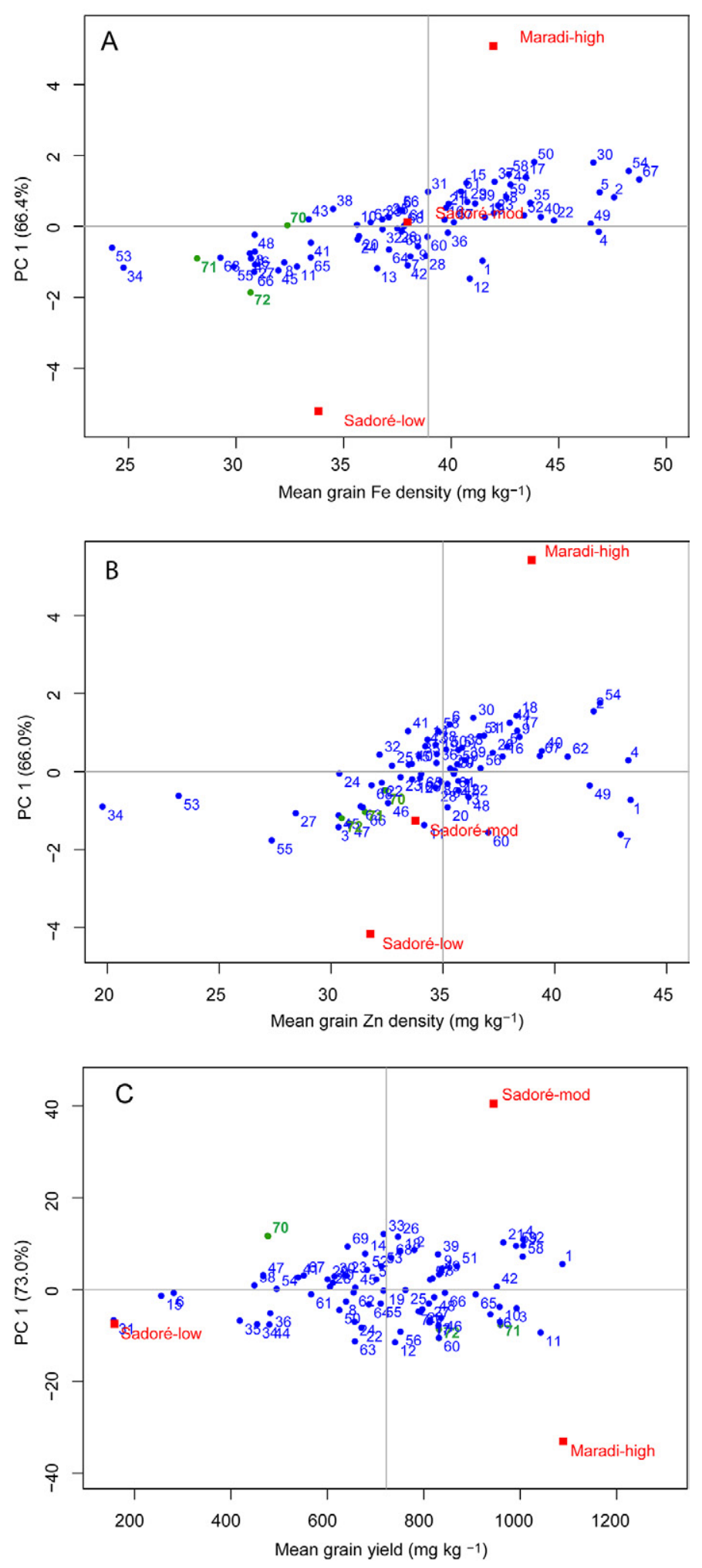

Figure 2. AMMI biplots for (A) grain Fe density, (B) Zn density, and (C) grain yield of 72 pearl millet [Pennisetum glaucum (L.) R. Br.] genotypes evaluated in three environments (Sadore-low = Sadore site without fertilizer application; Sadore-mod = Sadore site with moderate fertilizer application; Maradi-high = Maradi site with high fertilizer application). The environment and genotype means are shown on the abscissa, with a vertical gray line at the grand means. Principal component (PC) 1 scores are given on the ordinate, with a horizontal gray line at zero. Entry numbers of the improved open-pollinated variety are marked in green. between $\mathrm{P}$ and $\mathrm{Ca}(r=0.79)$ and $\mathrm{Zn}$ and $\mathrm{Fe}(r=0.62)$. Significant negative correlations among minerals were not observed, even when each environment was observed separately (Supplemental Table S2). The range of variation among the correlation coefficients estimated for the three environments separately was quite variable for the different pairs of minerals. For instance, the correlation range between $\mathrm{Mg}$ and $\mathrm{P}$ was relatively low $(r=0.71-0.88)$, indicating a low environmental effect on the relationship of those two minerals.

Estimated correlation coefficients between grain yield and the observed minerals were slightly negative, but none of them was significant (Table 4). The ranges of those correlations were generally high, showing considerable influence of the environment on the association between grain yield and minerals (Supplemental Table S2).

Thousand-kernel weight showed a significant increase with higher grain Mg density $(p<0.01)$ but did not show any significant association with other minerals. Whole and decorticated grain mineral densities were highly significant $(p<0.001)$ and positively correlated for each observed mineral with coefficients ranging from 0.25 $(\mathrm{Mg})$ to $0.84(\mathrm{Fe})$ (Table 5).

\section{Geographic Distribution}

Latitude and longitude of the pearl millet genotypes' geographic origins did not show a significant association with grain density of any mineral (data not shown). A map showing the origin of the genotypes and their levels of grain $\mathrm{Zn}$ and $\mathrm{Fe}$ densities on the basis of adjusted means across environments (Fig. 3) supports this observation that there is no trend for grain mineral density with either latitude or longitude. However, the WCA map indicates some geographic patterns. For instance, genotypes originating from southeast Mali seem to have generally higher grain $\mathrm{Zn}$ and Fe concentrations than do genotypes from southwest Mali.

\section{DISCUSSION}

\section{Genetic Variation for Grain Mineral Densities in West and Central African Pearl Millets}

A crucial point for the success of any breeding program is access to sufficient genetic variation for the target trait within the available germplasm. Our study shows that for all tested minerals a moderate to high range in grain density exists among the WCA pearl millet genotypes assessed. Studies on grain $\mathrm{Zn}$ and Fe densities in pearl millet material grown in India reported ranges of 30 to $80 \mathrm{mg} \mathrm{kg}^{-1} \mathrm{Fe}$ and 20 to $70 \mathrm{mg} \mathrm{kg}^{-1} \mathrm{Zn}$ on the basis of the means of two environments (Velu et al., 2007; Govindaraj et al., 2013), which are considerably wider than the ranges we observed. Another study focusing on the grain density of several minerals in 225 Sudanese pearl millet genotypes evaluated in Sudan (Bashir et al., 2013) also found wider grain density ranges for all eight minerals 
Table 4. Coefficients of phenotypic correlations among grain mineral densities and between grain mineral densities and agronomic traits (TKW, thousand-kernel weight; GY, grain yield; FLO, flowering time). Mean coefficients are based on the correlation coefficients determined at three environments (Sadore-low = Sadore site without fertilizer application; Sadore-mod = Sadore site with moderate fertilizer application; Maradi-high = Maradi site with high fertilizer application) separately, which were calculated by the adjusted means of 72 pearl millet [Pennisetum glaucum (L.) R. Br.] genotypes.

\begin{tabular}{|c|c|c|c|c|c|c|c|c|c|c|}
\hline & $\mathrm{Mg}$ & $P$ & $\mathrm{~K}$ & $\mathrm{Ca}$ & Mn & $\mathrm{Fe}$ & $\mathrm{Cu}$ & $\mathrm{Zn}$ & TKW & GY \\
\hline $\mathrm{P}$ & $0.79^{*}$ & & & & & & & & & \\
\hline $\mathrm{K}$ & 0.32 & 0.31 & & & & & & & & \\
\hline $\mathrm{Ca}$ & 0.22 & -0.02 & $0.48^{\star \star}$ & & & & & & & \\
\hline $\mathrm{Mn}$ & $0.39^{*}$ & 0.3 & $0.42^{\star *}$ & $0.38^{*}$ & & & & & & \\
\hline $\mathrm{Fe}$ & 0.22 & 0.24 & $0.24^{*}$ & 0.07 & 0.29 & & & & & \\
\hline $\mathrm{Cu}$ & 0.49 & 0.34 & 0.31 & $0.46^{\star \star}$ & 0.26 & 0.37 & & & & \\
\hline $\mathrm{Zn}$ & 0.33 & $0.46^{\star \star}$ & -0.04 & -0.11 & 0.18 & $0.62^{\star \star}$ & 0.27 & & & \\
\hline TKW & $-0.35^{\star \star}$ & -0.27 & 0.12 & 0.09 & -0.11 & 0.07 & 0 & -0.18 & & \\
\hline GY & -0.25 & -0.13 & -0.23 & -0.18 & -0.17 & -0.02 & -0.17 & -0.05 & 0.24 & \\
\hline FLO & 0.14 & -0.09 & 0.3 & $0.48^{* *}$ & 0.19 & 0.13 & $0.47^{\star \star}$ & -0.1 & 0 & $-0.34^{\star \star}$ \\
\hline
\end{tabular}

* Significant at $P<0.05$ at all three locations.

${ }^{*}$ Significant at $P<0.01$ at all three locations.

Table 5. Correlation coefficients $(r)$ between whole and decorticated grain mineral densities.

\begin{tabular}{cc}
\hline Minerals & $r$ \\
\hline $\mathrm{Mg}$ & $0.26^{\star \star \star}$ \\
$\mathrm{P}$ & $0.40^{\star \star \star}$ \\
$\mathrm{K}$ & $0.30^{\star \star \star}$ \\
$\mathrm{Ca}$ & $0.56^{\star \star \star}$ \\
$\mathrm{Mn}$ & $0.79^{\star \star \star}$ \\
$\mathrm{Fe}$ & $0.82^{\star \star \star}$ \\
$\mathrm{Cu}$ & $0.47^{\star \star \star}$ \\
$\mathrm{Zn}$ & $0.81^{\star \star \star}$ \\
\hline
\end{tabular}

*** Significant at $P<0.001$.

than did the present study. One explanation for this might be the larger number of genotypes evaluated in the study by Bashir et al. (2013). Further, it has to be considered that ranges given by Bashir et al. (2013) refer to entry means of one location only (irrigated and fertilized), whereas we refer to entry means of three locations, including one low soil fertility environment, which had the effect of shrinking the range toward the mean. In general, means of the eight mineral densities reported by Bashir et al. (2013) were similar to what has been found in our study.

PE05980, the landrace with the highest Fe density mean over locations $\left(48.7 \mathrm{mg} \mathrm{kg}^{-1}\right)$, reached an Fe density of $61.6 \mathrm{mg} \mathrm{kg}^{-1}$ at the Maradi-high environment. This indicates the potential of the variety in high-input environments, but on the other hand, a certain inferiority compared with the Indian variety, ICTP 8203-Fe, containing $77 \mathrm{mg} \mathrm{kg}^{-1}$ (Saltzman et al., 2013). This underlines the potential of ICTP 8203-Fe, and other high-Fe pearl millet breeding materials and experimental lines developed by breeding programs in other parts of the world (from Georgia, Kansas, and Nebraska in the United States to ICRISAT breeding programs in India, Niger, and Zimbabwe and state, national, and/or regional programs in Brazil, Eritrea, Ghana, India, Namibia, Sudan, and
Uganda), to be used for introgression of more favorable alleles into WCA pearl millet breeding populations.

\section{Stability of Grain Micronutrient Densities in Pearl Millet}

Numerous complex factors, such as the genotype, soil, fertilization rates, and other environmental conditions, influence grain mineral densities (House, 1999). In our study, most grain mineral densities were significantly affected by environmental effects (Table 3 ).

A trend of increasing grain $\mathrm{Zn}$ and Fe density through fertilization was observed in this study (Fig. 1) and is in line with other studies on wheat (Shi et al., 2010; Cakmak et al., 2010; Kutman et al., 2011) and maize (Ciampitti and $\bar{V} y n, 2013)$. However, since a direct comparison of low versus high input conditions was only done at one location (Sadoré), a validation of the fertilization effect at different locations (or years) is needed to derive more sound conclusions. Kutman et al. (2011) showed additionally that Zn and $\mathrm{Fe}$ concentrations increased in all fractions of wheat grains. Those results of Kutman et al. (2011) seem to be transferable to pearl millet, as we also found an increasing trend in $\mathrm{Fe}$ and $\mathrm{Zn}$ densities for whole as well as decorticated grains through fertilization (Fig. 1). On the basis of the observed trends in our study, which conform with other reported literature as outlined above, it appears that improved soil fertility can be an effective tool for agronomic biofortification and will be complementary to biofortification breeding. However, the availability of fertilizer is limited for most small-scale farmers in Sahelian Africa, and often unaffordable because of the high cost of surface transportation due to poor roads and inadequate railroad infrastructure, thus suggesting that agronomic biofortification could be less feasible than genetic biofortification, at least in the short term.

The significant $G \times E$ interaction effects for grain $\mathrm{Fe}$ and $\mathrm{Zn}$ indicate significant differences in responses 

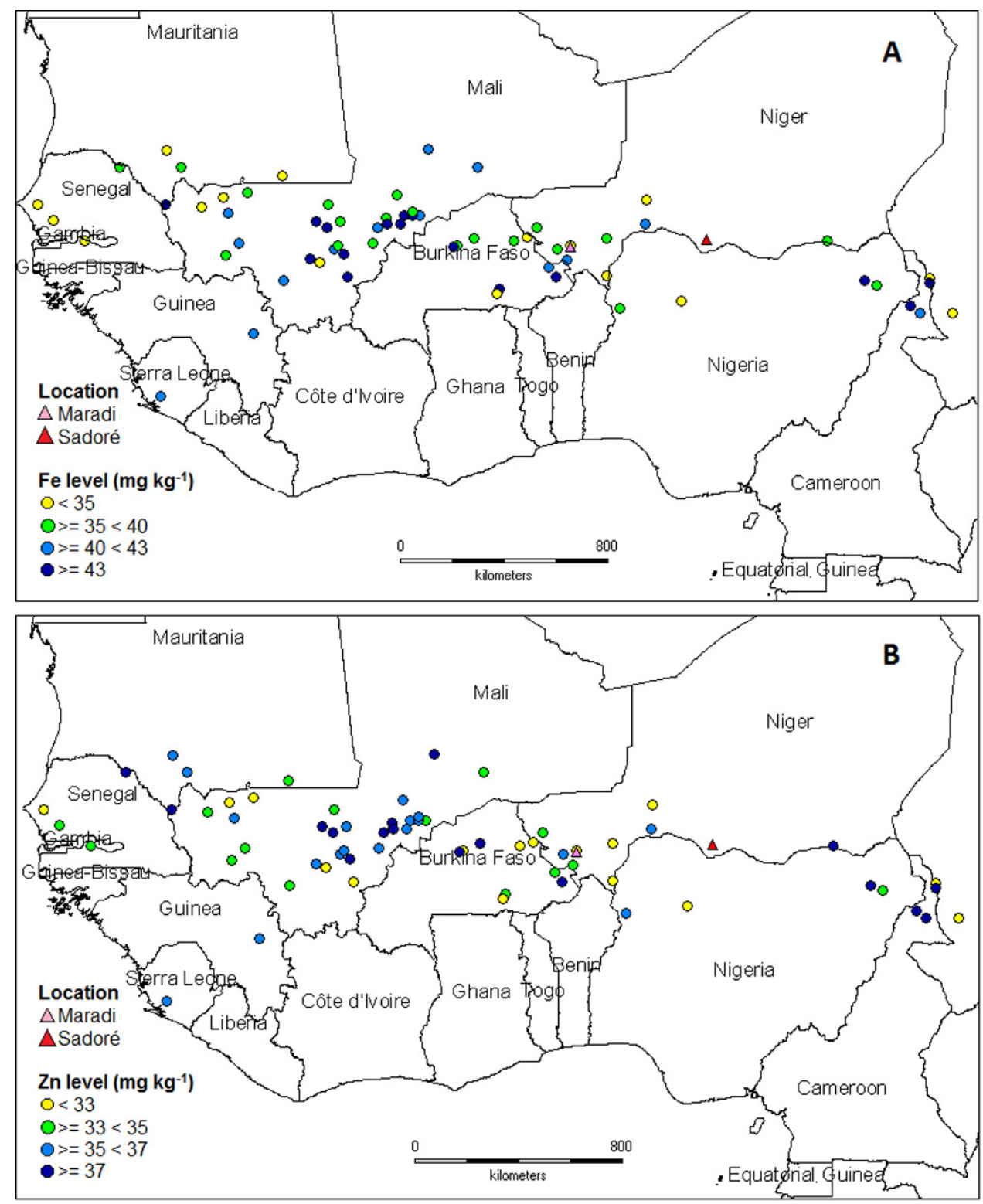

Figure 3. Geographic origin of the 72 pearl millet [Pennisetum glaucum (L.) R. Br.] genotypes (points) and their differentiation in whole grain (A) Fe and (B) Zn density. Experimental locations are marked as triangles.

of different genotypes to the three testing environments used in this study. This points to the importance of multienvironment trials and analysis of $\mathrm{G} \times \mathrm{E}$ interaction patterns to either identify stable genotypes suitable for a wide range of environmental conditions, or genotypes with specific adaptation to a specific type of environment, for example, low-input or intensified-production conditions. On the basis of the AMMI biplot (Fig. 2), pearl millet genotypes exhibiting relatively high Fe density, Zn density, and grain-yield performance that was stable over environments could be identified. Landraces PE00012 and PE05665 seem especially interesting, as they were also above average for grain $\mathrm{Zn}, \mathrm{Fe}$, and yield at Sadoré-low (Supplemental Table S1). Further evaluation under onfarm, low-input conditions could confirm the potential of these genotypes to perform well on poor soils. Promising genotypes identified in this study should be used as base materials in future biofortification breeding programs for WCA. Introgression of breeding materials developed elsewhere that are known to be rich in mineral nutrients should also be exploited to enhance the potential of biofortified pearl millet OPVs and hybrids adapted to Sahelian and/or Sudanian agroecologies in WCA.

\section{Effect of Environmental Conditions on Selection Efficiency Targeting Biofortification}

The very low repeatabilities of grain mineral densities, except for $\mathrm{Zn}, \mathrm{K}$, and $\mathrm{Cu}$, observed in the Sadoré-low test environment indicate that grain mineral density differences of genotypes were not well distinguished under our low-input test conditions, which agrees with studies on grain legumes (Høgh-Jensen et al., 2006). The ability to detect grain mineral density differences was markedly 
improved under moderate- and high-input conditions (Sadoré-mod and Maradi-high, respectively), where considerably higher repeatabilities were found for all grain mineral densities. Direct selection for grain yield under low soil-phosphorus conditions has been recommended for sorghum (Leiser et al., 2012). The Sadoré-low selection environment probably best represents on-farm conditions for poor smallholders in WCA and would therefore best represent a direct selection environment. However, reasonable repeatability is a prerequisite for successful selection. Looking at whole-grain Fe densities, the very low repeatability in the Sadoré-low environment (0.28) compared with Sadoré-mod (0.84) and Maradi-high (0.83) suggests that selection would be more successful based on moderate- or high-input evaluations. However, since there was only one low-input environment, a preferable selection strategy cannot be ultimately recommended on the basis of this study. Further studies are needed to demonstrate whether repeatabilities for Fe grain densities are generally low under low-input conditions, across a wider geographic range of test sites and more diverse array of crop management conditions. Repeatabilities for mineral densities reported by Bashir et al. (2013), which were obtained from a single well-fertilized trial, were higher than our study for all grain mineral densities assessed. This difference might be explained by higher soil fertilities and greater field uniformity in the Wad Medani irrigated high-input environment compared with the conditions for the trials reported here.

\section{Prospects for Biofortification Breeding in West African Pearl Millet}

The significant and ample genetic variation, as well as sufficiently high heritabilities, observed for most whole- and decorticated-grain mineral densities in this study indicates the feasibility of biofortification breeding for pearl millet in Niger (Table 2). Comparing heritabilities of grain $\mathrm{Fe}$ and $\mathrm{Zn}$ densities of whole and decorticated grains, which are most important for biofortification, it appears that heritability values for $\mathrm{Fe}$ were considerably higher than those for $\mathrm{Zn}$, which has been found in maize as well (Baxter et al., 2012). In our study, this is mainly caused by the higher $G \times E$ interaction effects relative to genetic effects for $\mathrm{Zn}$. The $\mathrm{G} \times$ E interaction effects for $\mathrm{Zn}$ are even higher for whole-grain than for decorticated-grain density, resulting in higher heritabilities for decorticated grain samples. Previous studies on pearl millet have shown a significant $G \times E$ interaction effect for whole-grain densities of Fe and $\mathrm{Zn}$ as well (Gupta et al., 2009; Velu et al., 2011; Govindaraj et al., 2013), indicating the general importance of basing biofortification breeding programs on multiple environment testing.

\section{Effects of Biofortification on Other Traits}

Biofortification breeding is usually focused on the most limited nutrients in human diets such as $\mathrm{Zn}$ and Fe, without considering other essential minerals. Therefore it is crucial to know the interrelationship among target mineral grain densities and nontarget but nutritionally valuable minerals. In this study, no significant negative correlation has been observed between mineral grain densities, indicating that selection for target mineral grain densities would not reduce the grain density of most other minerals. This is in line with studies on pearl millet (Bashir et al., 2013) and other crops such as rice (Garcia-Oliveira et al., 2009) and spelt wheat (Gomez-Becerra et al., 2010).

Our results showed that in particular, $\mathrm{Zn}$ and $\mathrm{Fe}$ grain densities had a strong positive correlation $(r=0.73)$, showing that simultaneous selection for high $\mathrm{Zn}$ and Fe densities could be very efficient. This high correlation between $\mathrm{Zn}$ and Fe has already been reported in pearl millet (Velu et al., 2007; Govindaraj et al., 2009; Bashir et al., 2013), wheat (Gomez-Becerra et al., 2010; Velu et al., 2012) and pigeonpea [Cajanus cajan (L.) Millsp.] (Høgh-Jensen et al., 2006). Positive associations among grain mineral densities indicate that some physiological functions responsible for nutrient uptake and translocation are interconnected or do not discriminate $\mathrm{Fe}$ and $\mathrm{Zn}$, and other minerals. The often wide ranges of pairwise mineral correlations determined across the different environments showed a considerable impact of the soil conditions on the minerals composition (Supplemental Table S2).

Yield of economic products is generally the most important trait in plant breeding, thus the relationship of grain yield to mineral grain density is of great interest. This study showed that grain yield was not significantly associated with mineral density (Table 4). This is in line with the results obtained by Govindaraj et al. (2009) and Gupta et al. (2009), who studied correlations between agromorphological traits and mineral densities.

The high range of the correlations determined between mineral densities and grain yield across the individual environments showed that these correlations are considerably affected by environmental effects. Looking at Maradi-high separately (Supplemental Table S2) revealed significant negative correlations between minerals and grain yield in a high-input environment. These negative correlations might be explained by a dilution effect, which occurs if the extent of grain endosperm increase is higher than the increase of mineral rich bran and embryo.

In the high-input environment, it appears that grain yield and mineral micronutrient density variation is largely a function of flowering time, where long duration varieties having lower grain yields but higher grain mineral micronutrient densities (Supplemental Table S2). This might be because a longer growing period enables a longer period of mineral accumulation. 


\section{The Specific Role of Phytate}

The bioavailability of minerals is known to be inhibited by the antinutrient phytate (Nolan et al., 1987), which is the major form of $\mathrm{P}$ in grain. A previous study on micronutrient availability of staple foods suggests that one should focus on low phytate:mineral molar ratio rather than the total mineral content (Pachón et al., 2009). Highly significant positive correlations between total grain $\mathrm{P}$ and grain phytate have been found in pearl millet (Govindaraj et al., 2009), rice (Stangoulis et al., 2006), and sorghum (Rattunde, personal communication, 28 Nov. 2012), demonstrating the potential of $\mathrm{P}$ as a phytate indicator. Using $\mathrm{P}$ to predict phytate for biofortification programs would be very expedient as $\mathrm{P}$ is by far less costly to analyze than phytate. Further, screening for moderate levels of free phosphate (inorganic $\mathrm{P}$ ) combined with total $\mathrm{P}$ grain density should permit relatively low-cost identification of moderate-phytate genotypes having acceptable grain yield performance combined with better bioavailability for grain Fe and Zn (Raboy, 2001; Guttieri et al., 2004; Bowen et al., 2007), better bioavailability of total dietary Fe and $\mathrm{Zn}$ (Raboy, 2001; Sequiera et al., 2001; Guttieri et al., 2004), better efficiency of $\mathrm{P}$ fertilizer use (Parentoni et al., 2008), and reduced potential for $\mathrm{P}$ contamination of surface water by livestock waste produced when grain is fed to monogastric livestock (Eeckhout and De Paepe, 1994; Raboy, 2001; Parentoni et al., 2008). Our results demonstrate that selection for high Fe grain density and moderate to low phytate concentration in pearl millet would not be conflicting, as there was no significant association between $\mathrm{Fe}$ and $\mathrm{P}$ across environments (Table 4). This is in line with the results given by Govindaraj et al. (2009), who found no correlation between Fe and P. However, if we focus on Maradi-high, a significant positive correlation between $\mathrm{P}$ and $\mathrm{Fe}$ density was found, indicating smaller selection gain for a low phytate:mineral molar ratio if selection is done under high-input conditions (Supplemental Table S2). In the case of $\mathrm{Zn}$, our results are distinct from those given by Govindaraj et al. (2009), who found no correlation between $\mathrm{Zn}$ and $\mathrm{P}$. The positive correlation between $\mathrm{Zn}$ and $\mathrm{P}(r=0.46)$ found in our study indicates there may be some limitations regarding biofortification breeding. The recent study by Bashir et al. (2013) supports our observation of higher correlations between $\mathrm{Zn}$ and $\mathrm{P}$ grain densities than between those of $\mathrm{Fe}$ and $\mathrm{P}$ in pearl millet.

\section{Geographic Distribution of Nutritious Pearl Millet Germplasm in West Africa}

The geographic patterns of grain $\mathrm{Fe}$ and $\mathrm{Zn}$ densities among pearl millet genotypes of West African origin that were included in this study suggest that pearl millet genotypes from regions such as southeastern Mali or northern Cameroon have on average higher $\mathrm{Zn}$ and Fe densities than those from other regions (Fig. 3). This information will be valuable in future projects, aiming to exploit global collections of pearl millet germplasm to improve grain mineral micronutrient density. Focusing screening efforts on genotypes originating from regions with generally high $\mathrm{Fe}$ and $\mathrm{Zn}$ densities should be quite efficient as a protocol to find nutritionally valuable genotypes. Results of Bashir et al. (2013), who studied the geographic distribution within Sudan of pearl millet genotypes rich in mineral nutrients, are similar to those reported here as they did not find associations between mineral densities and longitude or latitude but did detect regions with relatively higher frequencies of mineral-rich genotypes.

\section{CONCLUSIONS}

The potential for Fe and $\mathrm{Zn}$ biofortification breeding programs using WCA pearl millet germplasm appears to be very promising. Even if the Fe level achieved to date in the pearl millet biofortification breeding program based in India seems not feasible in the short term because of the moderate variation detected within the genetic materials used in this study, selection to combine biofortification traits with good agronomic performance (and the necessary suite of abiotic stress tolerances, biotic stress resistances, and organoleptic traits demanded by pearl millet consumers) should be rewarding. To achieve biofortification targets of higher $\mathrm{Zn}$ and Fe densities than what can be expected on the basis of the materials evaluated in this study, screening of additional landraces and improved varieties and hybrid parents from around the world, and introgression of favorable alleles from the high-nutrient pearl millet genetic resources identified in India, will be needed.

Appropriate testing conditions that reflect farmers' conditions will be a crucial factor for biofortification breeding programs for pearl millet in WCA, as there is, on the one hand, a relatively high $G \times E$ interaction effect for grain $\mathrm{Fe}$ and $\mathrm{Zn}$ densities and, on the other hand, relatively low repeatabilities for grain mineral micronutrient concentrations under low-input conditions, which represent current target conditions. The lack of associations between grain yield and grain $\mathrm{Fe}$ and $\mathrm{Zn}$ densities, combined with favorable associations between grain $\mathrm{Fe}$ and $\mathrm{Zn}$ densities, should permit efficient breeding for nutritious and high-yielding pearl millet varieties (including hybrids as well as open-pollinated synthetics and composites), with potential to help reduce micronutrient malnutrition among WCA populations dependent on this miraculously variable, stress-tolerant, climate-change-ready cereal of the dry tropics.

\section{Acknowledgments}

The authors are grateful to the German Ministry for Economic Cooperation and Development (BMZ) for financial support to the field research presented here (GIZ project numbers 05.7860.9001.00 and 09.7860.1-001.00); to the HarvestPlus Challenge Program for financially supporting the grain-quality analyses; to the McKnight Foundation Collaborative Crop Research Program 
for the discretionary research funds provided to B.I.G. Haussmann, used to support A. Pucher, and to the Bill and Melinda Gates Foundation for financial support to C.T. Hash's salary and operations. This publication was finalized as part of the CGIAR Research Program on Dryland Cereals.

\section{References}

Andrews, D.J., and K. Anand Kumar. 1996. Use of the West African pearl millet landrace Iniadi cultivar development. Plant Genet. Resour. Newsl. 105:15-22.

Bashir, E.M., A.M. Ali, A.M. Ali, A.E. Melchinger, H.K. Parzies, and B.I.G. Haussmann. 2013. Characterization of Sudanese pearl millet germplasm for agro-morphological traits and grain nutritional values. Plant Genet. Resour. 1-13. doi:10.1017/S1479262113000233.

Baxter, I.R., J.L. Gustin, M. Settles, and O.a. Hoekenga. 2012. Ionomic characterization of maize kernels in the intermated B73 $\times$ Mo17 population. Crop Sci. 53:208-220 10.2135/cropsci2012.02.0135.

Birner, R., S.A. Kone, N. Linacre, and D. Resnick. 2007. Biofortified foods and crops in West Africa: Mali and Burkina Faso. AgBioForum. 10:192-200.

Bouis, H.E. 1999. Economics of enhanced micronutrient density in food staples. F. Crop. Res. 60:165-173. doi:10.1016/S03784290(98)00138-5

Bowen, D.E., E.J. Souza, M.J. Guttieri, V. Raboy, and J. Fu. 2007. A low phytic acid barley mutation alters seed gene expression. Crop Sci. 47:149-159. doi:10.2135/cropsci2006.07.0456tpg

Butler, D.G., B.R. Cullis, A.R. Gilmour, and B.J. Gogel. 2009. Mixed models for $S$ language environments. ASReml-r reference manual. Queensland Dep. of Primary Industries and Fisheries, Brisbane, Queensland, Australia.

Cakmak, I., M. Kalayci, Y. Kaya, A. Torun, N. Aydin, Y. Wang, Z. Arisoy, H. Erdem, A. Yazici, O. Gokmen, L. Ozturk, and W.J. Horst. 2010. Biofortification and localization of zinc in wheat grain. J. Agric. Food Chem. 58:9092-9102. doi:10.1021/jf101197h

Cercamondi, C.I., I.M. Egli, E. Mitchikpe, F. Tossou, C. Zeder, J.D. Hounhouigan, and R.F. Hurrell. 2013. Total iron absorption by young women from iron-biofortified pearl millet composite meals is double that from regular millet meals but less than that from post-harvest iron-fortified. J. Nutr. 143:1376-1382. doi:10.3945/ jn.113.176826

Ciampitti, I.A., and T.J. Vyn. 2013. Maize nutrient accumulation and partitioning in response to plant density and nitrogen rate: II. Calcium, magnesium, and micronutrients. Agron. J. 105:1645-1657. doi:10.2134/agronj2013.0126

De Mendiburu, F. 2012. Agricolae: Statistical procedures for agricultural research. R package version 1.1-3.

Dwivedi S.L., K. Sahrawat, K.N. Rai, M.W. Blair, M.S. Andersson, W. Pfeiffer. 2012. Nutritionally enhanced staple food crops. Plant Breeding Reviews 36:169-291. doi:10.1002/9781118358566.ch3

Eeckhout, W., and M. De Paepe. 1994. Total phosphorus, phytatephosphorus and phytase activity in plant feedstuffs. Anim. Feed Sci. Technol. 47:19-29. doi:10.1016/0377-8401(94)90156-2

Garcia-Oliveira, A.L., L. Tan, Y. Fu, and C. Sun. 2009. Genetic identification of quantitative trait loci for contents of mineral nutrients in rice grain. J. Integr. Plant Biol. 51:84-92. doi:10.1111/j.17447909.2008.00730.x

Gomez-Becerra, H.F., H. Erdem, A. Yazici, Y. Tutus, B. Torun, L. Ozturk, and I. Cakmak. 2010. Grain concentrations of protein and mineral nutrients in a large collection of spelt wheat grown under different environments. J. Cereal Sci. 52:342-349. doi:10.1016/j. jcs.2010.05.003
Goswami, A.K., K.P. Sharma, and K.L. Sehgal. 1969. Nutritive value of proteins of pearl millet of high-yielding varieties and hybrids. Br. J. Nutr. 23:913-916.

Govindaraj, M., K.N. Rai, P. Shanmugasundaram, S.L. Dwivedi, K.L. Sahrawat, R. Muthaiah, and S. Rao. 2013. Combining ability and heterosis for grain iron and zinc densities in pearl millet. Crop Sci. 53:507-517. doi:10.2135/cropsci2012.08.0477

Govindaraj, M., M. Selvi, and S. Rajarathinam. 2009. Correlation studies for grain yield components and nutritional quality traits in pearl millet [Pennisetum glaucum (L.) R. Br.] germplasm. Evolution (N. Y) 5:686-689.

Govindaraj, M., B. Selvi, S. Rajarathinam, and P. Sumathi. 2011. Genetic variability and heritability of grain yield components and grain mineral concentration in India's pearl millet [Pennisetum glaucum (L.) R. Br.] accessions. African J. Food. Agric. Nutr. Dev. 11:4758-4771.

Gupta, S.K., G. Velu, K.N. Rai, and K. Sumalini. 2009. Association of grain iron and zinc content with grain yield and other traits in pearl millet. Crop Improv. 36(2):4-7.

Guttieri, M., D. Bowen, J.A. Dorsch, V. Raboy, E. Souza, and P. Ins. 2004. Identification and characterization of a low phytic acid wheat. Crop Sci. 44:418-424. doi:10.2135/cropsci2004.0418

Haussmann, B.I.G., F.H. Rattunde, E. Weltzien-Rattunde, P.S.C. Traoré, K. vom Brocke, and H.K. Parzies. 2012. Breeding strategies for adaptation of pearl millet and sorghum to climate variability and change in West Africa. J. Agron. Crop Sci. 198:327-339. doi:10.1111/j.1439-037X.2012.00526.x

Høgh-Jensen, H., F.A. Myaka, D. Kamalongo, J. Rasmussen, and A. Ngwira. 2006. Effect of environment on multi-element grain composition of pigeonpea cultivars under farmers' conditions. Plant Soil 285:81-96. doi:10.1007/s11104-006-0060-x

House, W.A. 1999. Trace element bioavailability as exemplified by iron and zinc. F. Crop. Res. 60:115-141. doi:10.1016/S03784290(98)00136-1

Husted, S., B.F. Mikkelsen, J. Jensen, and N.E. Nielsen. 2004. Elemental fingerprint analysis of barley (Hordeum vulgare) using inductively coupled plasma mass spectrometry, isotope-ratio mass spectrometry, and multivariate statistics. Anal. Bioanal. Chem. 378:171-182. doi:10.1007/s00216-003-2219-0

Joy, E.J.M., S.D. Young, C.R. Black, E.L. Ander, M.J. Watts, and M.R. Broadley. 2012. Risk of dietary magnesium deficiency is low in most African countries based on food supply data. Plant Soil 368:129-137. doi:10.1007/s11104-012-1388-z

Khairwal, I.S., K.N. Rai, D.J. Andrews, and G. Harinarayana. 1999. Pearl millet breeding. Oxford \& IBH publishing Co. Pvt. Ltd., New Delhi.

Kodkany, B.S., R.M. Bellad, N.S. Mahantshetti, J.E. Westcott, N.F. Krebs, J.F. Kemp, and K.M. Hambidge. 2013. Biofortification of pearl millet with iron and zinc in a randomized controlled trial increases absorption of these minerals above physiologic requirements in young children. J. Nutr. 143:1489-1493. doi:10.3945/ jn.113.176677

Kumar, S. 2011. Development of new mapping population and marker-assisted improvement of iron and zinc grain density in pearl millet [Pennisetum glaucum (L.) R. Br.]. Ph.D. thesis, Swami Keshwanand Rajasthan Agricultural University, Bikaner, Rajasthan, India.

Kutman, U.B., B. Yildiz, and I. Cakmak. 2011. Improved nitrogen status enhances zinc and iron concentrations both in the whole grain and the endosperm fraction of wheat. J. Cereal Sci. 53:118125. doi:10.1016/j.jcs.2010.10.006

Leiser, W.L., H.F.W. Rattunde, H.-P. Piepho, E. Weltzien, A. Diallo, A.E. Melchinger, H.K. Parzies, and B.I.G. Haussmann. 2012. 
Selection strategy for sorghum targeting phosphorus-limited environments in West Africa: Analysis of multi-environment experiments. Crop Sci. 52:2517-2527. doi:10.2135/cropsci2012.02.0139

Meenakshi, J.V., N.L. Johnson, V.M. Manyong, H. DeGroote, J. Javelosa, D.R. Yanggen, F. Naher, C. Gonzalez, J. García, and E. Meng. 2010. How cost-effective is biofortification in combating micronutrient malnutrition? An ex ante assessment. World Dev. 38:64-75. doi:10.1016/j.worlddev.2009.03.014

Muthayya, S., J.H. Rah, J.D. Sugimoto, F.F. Roos, K. Kraemer, R.E. Black. 2013. The global hidden hunger indices and maps: An advocacy tool for action. PLoS ONE 8: e67860. doi:10.1371/ journal.pone.0067860

Nolan, K.B., P.A. Duffin, and D.J. Mcweeny. 1987. Effects of phytate on mineral bioavailability. In vitro studies on studies on $\mathrm{Mg}^{2+}$, $\mathrm{Ca}^{2+}, \mathrm{Fe}^{3+}, \mathrm{Cu}^{2+}$ and $\mathrm{Zn}^{2+}\left(\right.$ also $\mathrm{Cd}^{2+}$ ) solubilities in the presence of phytate. J. Sci. Food Agric. 40:79-85. doi:10.1002/jsfa.2740400110

Pachón, H., D.A. Ortiz, C. Araujo, M.W. Blair, and J. Restrepo. 2009. Iron, zinc, and protein bioavailability proxy measures of meals prepared with nutritionally enhanced beans and maize. J. Food Sci. 74:H147-H154. doi:10.1111/j.1750-3841.2009.01181.x

Parentoni, S.N., C. Lopes, and D.S. Júnior. 2008. Phosphorus acquisition and internal utilization efficiency in tropical maize genotypes. Pesqui. Agropecu. Bras. 43:893-901. doi:19.1590/S0100204 X2008000700014.

Pfeiffer, W.H., and B. McClafferty. 2007. HarvestPlus: Breeding crops for better nutrition. Crop Sci. 47:88-105. doi:10.2135/ cropsci2007.09.0020IPBS

R Development Core Team. 2012. R: A language and environment for statistical computing. 2.14.2. R Foundation for Statistical Computing, Vienna, Austria. http://www.R-project.org/ (accessed 25 Apr. 2014).

Raboy, V. 2001. Seeds for a better future: "Low phytate" grains help to overcome malnutrition and reduce pollution. Trends Plant Sci. 6:458-462. doi:10.1016/S1360-1385(01)02104-5

Rai, K.N., M. Govindaraj, and A.S. Rao. 2012. Genetic enhancement of grain iron and zinc content in pearl millet. Qual. Assur. Saf. Crop. Foods. 4:119-125. doi:10.1111/j.1757-837X.2012.00135.x

Rai, K., K. Kumar, D. Andrews, A. Rao, A. Raj, and J. Witcombe. 1990. Registration of 'ICTP 8203' pearl millet. Crop Sci. 30:959. doi:10.2135/cropsci1990.0011183X003000040048x
Saltzman, A., E. Birol, H.E. Bouis, E. Boy, F.F. De Moura, Y. Islam, and W.H. Pfeiffer. 2013. Biofortification: Progress toward a more nourishing future. Glob. Food Sec. 9-17. doi:10.1016/j. gfs.2012.12.003.

Sawaya, W.N., J.K. Khalil, and W.J. Safi. 1984. Nutritional quality of pearl millet flour and bread. Plant Foods Hum. Nutr. 34:117-125. doi:10.1007/BF01094839

Sequiera, E., S. Arruda, L. de Sousa, and E. de Souza. 2001. Phytate iron from an alternative dietary supplement has no effect on the calcium, iron and zinc status in undernourished rats. Arch. Latinoam. Nutr. 51(3):250-257.

Shi, R., Y. Zhang, X. Chen, Q. Sun, F. Zhang, V. Römheld, and C. Zou. 2010. Influence of long-term nitrogen fertilization on micronutrient density in grain of winter wheat (Triticum aestivum L.). J. Cereal Sci. 51:165-170. doi:10.1016/j.jcs.2009.11.008

Stangoulis, J.C.R., B.-L. Huynh, R.M. Welch, E.-Y. Choi, and R.D. Graham. 2006. Quantitative trait loci for phytate in rice grain and their relationship with grain micronutrient content. Euphytica 154:289-294. doi:10.1007/s10681-006-9211-7

Velu, G., K.N. Rai, V. Muralidharan, V.N. Kulkarni, T. Longvah, and T.S. Raveendran. 2007. Prospects of breeding biofortified pearl millet with high grain iron and zinc content. Plant Breed. 126:182-185. doi:10.1111/j.1439-0523.2007.01322.x

Velu, G., K.N. Rai, V. Muralidharan, T. Longvah, and J. Crossa. 2011. Gene effects and heterosis for grain iron and zinc density in pearl millet [Pennisetum glaucum (L.) R. Br]. Euphytica 180:251259. doi:10.1007/s10681-011-0387-0

Velu, G., K.N. Rai, K.L. Sahrawat, and K. Sumalini. 2008. Variability for grain iron and zinc contents in pearl millet hybrids. J. SAT Agric. Res. 6:1-4.

Velu, G., R.P. Singh, J. Huerta-Espino, R.J. Peña, B. Arun, A. Mahendru-Singh, M.Y. Mujahid, V.S. Sohu, G.S. Mavi, J. Crossa, G. Alvarado, A.K. Joshi, and W.H. Pfeiffer. 2012. Performance of biofortified spring wheat genotypes in target environments for grain zinc and iron concentrations. F. Crop. Res. 137:261-267. doi:10.1016/j.fcr.2012.07.018

White, P.J., and M.R. Broadley. 2005. Biofortifying crops with essential mineral elements. Trends Plant Sci. 10:586-593. doi:10.1016/j. tplants.2005.10.001 